\title{
Possible Incompatibility between Amino Acids and Copper in Solutions for Pediatric Parenteral Nutrition
}

\author{
Maxime Thibault
}

\section{INTRODUCTION}

$\mathrm{T}$ he nutrient formulas used for parenteral nutrition are highly complex admixtures of multiple solutions, infused by the IV route to patients who are unable to receive nutrition by mouth or by the enteral route. The administered products contain macronutrients (amino acids, dextrose, and lipids), electrolytes (sodium, potassium, calcium, phosphate, magnesium, chloride, and acetate), micronutrients (vitamins, trace elements), and water. The solution for parenteral administration can be prepared as a " 2 -in-1" solution, with lipids being infused separately from the other components, or as a "3-in-1" admixture, in which all components are mixed together.

The complexity of these solutions poses a significant risk of incompatibility between components. The most widely known incompatibility involving components of parenteral nutrition solutions is precipitation of calcium phosphate. In 1994, the US Food and Drug Administration published a safety communication describing cases of incompatibility between calcium and phosphate in parenteral nutrition solutions, in which infusion of the solutions resulted in death (2 patients) or respiratory distress ( 2 patients). ${ }^{2}$ Measures taken to prevent adverse events related to incompatibilities include the use of filters during infusion, specifically $0.22-\mu \mathrm{m}$ filters for 2 -in-1 solutions and 1.2- $\mu \mathrm{m}$ filters for 3-in-1 admixtures. For compounded parenteral nutrition solutions, components should be added in the same order every time, and contact between incompatible solutions should be minimized. ${ }^{3}$ Specifically, phosphates should be added at the beginning of the mixing sequence, and calcium gluconate should be added last, such that the calcium is added when the volume of the solution being compounded is at its maximum. ${ }^{1}$ The solubility of calcium phosphate should be evaluated for all parenteral nutrition orders, using validated solubility curves specific to the brand of amino acids used. ${ }^{2}$ Pharmacists preparing and validating parenteral nutrition orders should always inspect bags for visually detectable precipitates before releasing them for infusion.

Unfortunately, the measures described above do not always prevent incompatibilities in parenteral nutrition solutions. This report describes visual observation of precipitates in 3 different parenteral nutrition solutions.

\section{CASES}

All parenteral nutrition solutions administered within the study hospital are prepared in the pharmacy in a laminar flow hood located in a clean room, in conformity with USP Chapter $<797>$ guidelines. ${ }^{4}$ All orders for parenteral nutrition are compounded daily, using a Baxa ExactaMix 2400 automated compounder (Baxa, Markham, Ontario; precision of delivery $0.01 \mathrm{~mL}$ ). Each order is entered into a computer program, which validates all parameters related to the solution, including solubility of calcium phosphate. The mixing order of the components is in keeping with recommendations to avoid precipitation of calcium phosphate, and all bags are inspected visually before delivery. Two-in-one solutions are used exclusively, with lipids administered into the IV tubing via a Y-site connector placed beyond the $0.22-\mu \mathrm{m}$ filter. All 2-in-1 bags are protected from light during infusion. ${ }^{5}$

On a single day, the pharmacy was notified of 3 separate cases of a yellow-brown substance accumulating on the $0.22-\mu \mathrm{m}$ filter during administration of parenteral nutrition solutions. Visual examination of the filters showed an apparently solid brown substance suspended in the yellow 2-in-1 solution (Figure 1). The composition of each solution is presented in Table 1, and the corresponding prescriptions are shown in Table 2 . A possible compatibility issue was suspected. The calcium and phosphate concentrations were within acceptable limits for the amino acid concentrations, so calcium 
Table 1. Volumes of Components Used to Prepare Parenteral Nutrition Solutions that Exhibited Precipitate

\begin{tabular}{|c|c|c|c|}
\hline \multirow[b]{2}{*}{ Component } & \multicolumn{3}{|c|}{ Solution; Volume of Component $(\mathrm{mL})$} \\
\hline & Solution 1 & Solution 2 & Solution 3 \\
\hline Pediatric amino acids $10 \%$ (Primene) $^{\star}$ & 170.75 & 161.42 & 197.44 \\
\hline Dextrose $70 \%$ * & 91.47 & 110.69 & 122.23 \\
\hline Sterile water* & 108.33 & 279.77 & 299.06 \\
\hline Sodium chloride, $4 \mathrm{mmol} / \mathrm{mL} \dagger$ & 2.38 & 1.38 & 3.23 \\
\hline Sodium acetate, $4 \mathrm{mmol} / \mathrm{mL} \dagger$ & 3.72 & 2.15 & 1.31 \\
\hline Potassium acetate, $4 \mathrm{mmol} / \mathrm{mL} \neq$ & 3.74 & 6.46 & 4.94 \\
\hline Calcium gluconate, $0.232 \mathrm{mmol} / \mathrm{mL} \dagger$ & 14.69 & 16.66 & 12.74 \\
\hline $\begin{array}{l}\text { Sodium glycerophosphate, } \\
1 \mathrm{mmol} / \mathrm{mL} \S\end{array}$ & 2.74 & 9.08 & 2.44 \\
\hline Magnesium sulphate, $200 \mathrm{mg} / \mathrm{mL} \dagger$ & 1.07 & 0.97 & 0.66 \\
\hline $\begin{array}{l}\text { Pediatric multivitamin } \\
\text { (Multi-12/K1 Pediatric) }\end{array}$ & 6.57 & 5.98 & 5.89 \\
\hline Ranitidine, $25 \mathrm{mg} / \mathrm{mL}+$ & 1.84 & 1.91 & 0.71 \\
\hline Copper, $100 \mu \mathrm{g} / \mathrm{mL} \dagger$ & 1.71 & 2.58 & 1.32 \\
\hline lodine, $25 \mu \mathrm{g} / \mathrm{mL}+$ & 2.05 & 3.1 & 1.58 \\
\hline Selenium, $10 \mu \mathrm{g} / \mathrm{mL} \dagger$ & 1.71 & 2.58 & 1.32 \\
\hline Zinc, $1 \mathrm{mg} / \mathrm{mL} \dagger$ & 2.82 & 3.04 & 2.42 \\
\hline Heparin, 100 units $/ \mathrm{mL}$ & 0 & 3.23 & 3.95 \\
\hline Iron dextran, $1 \mathrm{mg} / \mathrm{mL} \dagger$ & 3.42 & 0 & 2.63 \\
\hline
\end{tabular}

*Manufacturer: Baxter Corporation, Mississauga, Ontario.

†Manufacturer: Pharmaceutical Partners of Canada, Richmond Hill, Ontario.

¥Manufacturer: Sandoz, Boucherville, Quebec.

$\S M a n u f a c t u r e r:$ Fresenius Kabi, Bad Homburg, Germany.

IManufacturer: B-Braun Medical, Allentown, Pennsylvania.

Table 2. Prescribed Composition of Parenteral Nutrition Solutions that Exhibited Precipitate

\begin{tabular}{|c|c|c|c|}
\hline Prescribed Component & Solution 1 & Solution 2 & Solution 3 \\
\hline Child's weight* $(\mathrm{kg})$ & 10.8 & 6.5 & 5.62 \\
\hline $\begin{array}{l}\text { PN fluids prescribed, including } \\
\text { lipids ( } \mathrm{mL} / \mathrm{kg} \text { daily) }\end{array}$ & 50 & 60 & 115 \\
\hline Amino acids (g/kg daily) & 1.25 & 2 & 3 \\
\hline Dextrose (g/kg daily) & 6 & 7.5 & 13 \\
\hline Lipidst (g/kg daily) & 0.8 & 1.2 & 1.8 \\
\hline Sodium (mmol/kg daily) & 2.5 & 3.5 & 3.5 \\
\hline Potassium (mmol/kg daily) & 2 & 1.75 & 3 \\
\hline Calcium (mmol/kg daily) & 0.3 & 0.4 & 0.45 \\
\hline Phosphate (mmol/kg daily) & 0.74 & 0.48 & 0.58 \\
\hline Magnesium (mmol/kg daily) & 0.06 & 0.1 & 0.08 \\
\hline$\%$ acetate (versus chloride) & 80 & 70 & 60 \\
\hline Multivitamins (mL/day) & 5 & 5 & 5 \\
\hline Ranitidine (mg/kg daily) & 3.7 & 5.4 & 2.7 \\
\hline Copper ( $\mu \mathrm{g} / \mathrm{kg}$ daily) & 20 & 20 & 20 \\
\hline lodine ( $\mu \mathrm{g} / \mathrm{kg}$ daily) & 6 & 6 & 6 \\
\hline Selenium ( $\mu \mathrm{g} / \mathrm{kg}$ daily) & 2 & 2 & 2 \\
\hline Zinc ( $\mu g / k g$ daily) & 235 & 331 & 368 \\
\hline Heparin (units/mL) & 0.5 & 0 & 0.5 \\
\hline Iron ( $\mu \mathrm{g} / \mathrm{kg}$ daily) & 0 & 400 & 400 \\
\hline
\end{tabular}

PN = parenteral nutrition.

${ }^{*}$ As recorded on prescription.

†Not included in compounded solution; administered separately. 


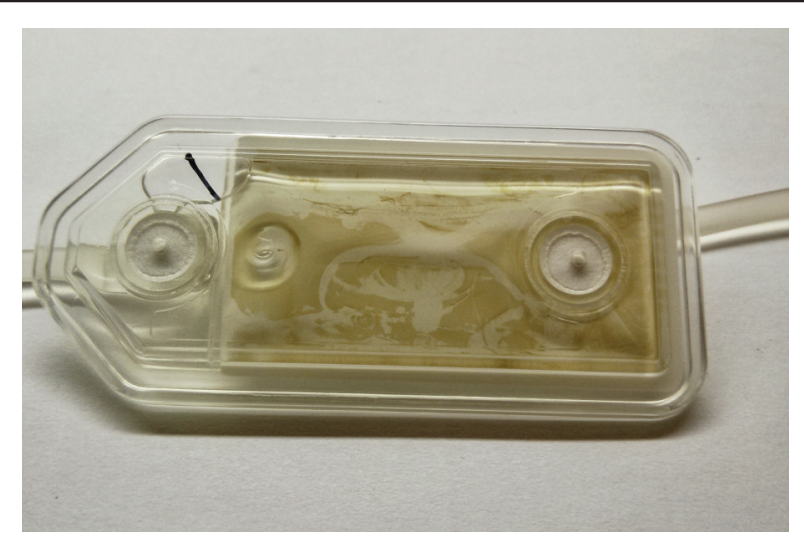

Figure 1. Precipitate observed on a $0.22-\mu \mathrm{m}$ filter used for administration of parenteral nutrition solution.

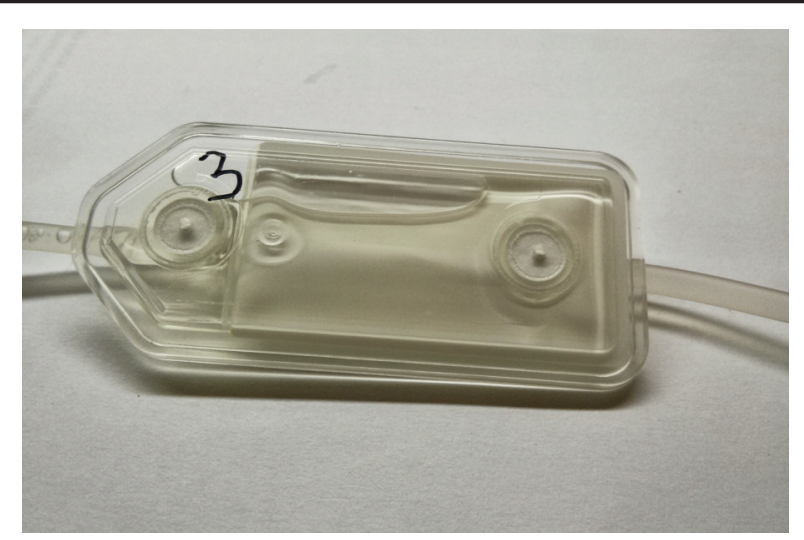

Figure 2. Filter $(0.22 \mu \mathrm{m})$ after infusion of parenteral solution prepared with a different brand of amino acids. phosphate precipitates were ruled out. Only 2 of the solutions contained iron, and only 2 contained heparin; therefore, these components were excluded as possible causes of the incompatibility. All 3 solutions contained the same brand of pediatric amino acids (Primene, Baxter Corporation, Mississauga, Ontario). All patients in the hospital were temporarily switched to a different brand of amino acids pending investigation of the issue. The precipitation problem did not recur after this switch.

To determine the components responsible for the incompatibility, solution 1 was re-created in the pharmacy and infused in a mock clinical setting at the prescribed rate through a $0.22-\mu \mathrm{m}$ filter. After the infusion was complete, the same substance was visible on the filter as was observed in the sentinel cases. Modified solutions were compounded and tested, one with a different brand of amino acids (Travasol Blend C, Baxter Corporation, Mississauga, Ontario), one without phosphate, one without multivitamins, and one without trace elements. The solutions without phosphate or multivitamins produced a precipitate similar to the case findings, but the solution with different amino acids and the solution without trace elements failed to produce the precipitate, which suggested possible contributions from these components (Figure 2). A subsequent series of identical solutions were prepared, with each solution excluding one of the trace elements (copper, iodine, selenium, or zinc.) All of these solutions produced the precipitate with filtering, except the solution devoid of copper (Micro Cu, Sandoz, Boucherville, Quebec). To investigate the role of admixture concentration in causing the precipitate, a more dilute solution was compounded, using the same quantity of additives, including all trace elements, and twice the amount of diluent. This solution failed to produce the precipitate when filtered (Figure 3).



Figure 3. Filter $(0.22 \mu \mathrm{m})$ after infusion of diluted parenteral nutrition solution.

The issue was reported to the manufacturer of the amino acid product. Each of the 3 parenteral nutrition solutions had been partially infused to the patient for whom it had been prescribed, but none of the patients reported symptoms or presented signs that could be attributed to infusion of the precipitate. No additional laboratory tests or imaging studies were performed because of the absence of clinical manifestations. It was hypothesized that the use of $0.22-\mu \mathrm{m}$ filters prevented the precipitate from reaching the patients.

\section{DISCUSSION}

In test situations with variants of one of the solutions involved in the sentinel cases, no precipitate was observed when 
a different amino acid preparation was used or when copper was omitted. On the basis of these results the observed problem was attributed to an incompatibility between the specific type of amino acids used in the original solutions and cupric sulphate.

Compared with the alternative product that did not cause precipitation, the amino acid solution implicated in the 3 sentinel cases contained cysteine and had a lower $\mathrm{pH}$. This type of amino acid solution is commonly used in neonatology, because the lower $\mathrm{pH}$ allows for better solubility of calcium phosphate and because cysteine has been described as a conditionally essential amino acid in this population. ${ }^{6}$ It is possible that the incompatibility could be a result of these features of the amino acid solution. Testing excluded heparin, iron, multivitamins, phosphate, selenium, iodine, and zinc as direct causes of the incompatibility, because the precipitate was observed in solutions prepared without these components. Copper is an essential trace element that must be added to parenteral nutrition solutions, especially for patients receiving little or no nutrition by other means. Copper deficiency may lead to hematologic disturbances, bone abnormalities, and other problems, all of which have been observed in patients receiving copper-free parenteral nutrition. ${ }^{78}$ Removing copper from the solution would therefore be inappropriate in this situation.

In a previous study of trace element stability in parenteral nutrition solutions, Allwood and others found that use of cysteine-containing amino acid solutions in conjunction with copper might be problematic. The study authors suggested 2 hypotheses to explain this type of precipitation": a direct reaction between copper and cysteine resulting in precipitation of copper cysteinate or a reaction between hydrogen sulphide (produced by degradation of cysteine to cystine during thermal sterilization) and copper to produce a precipitate of copper sulphide. In another study, ${ }^{10}$ solutions prepared with amino acids that did not contain cysteine did not exhibit this type of precipitate.

Precipitation did not seem to occur in the diluted test solution, so concentration may be a factor in the observed reaction. The 3 parenteral nutrition solutions involved in the sentinel cases contained higher concentrations of copper and other trace elements than the hospital's usual formulations because they were destined for administration to patients who were in transition from parenteral to enteral or oral nutrition. It was clinically desirable for these patients to receive less water than usual via the parenteral route, but they received the full dose of copper, since it is common practice to provide the full recommended daily doses of trace elements up to discontinuation of parenteral nutrition. The most dilute solution exhibiting a precipitate in the sentinel cases provided $101 \mathrm{~mL} / \mathrm{kg}$ of fluids and $20 \mu \mathrm{g} / \mathrm{kg}$ of copper daily. In comparison, premature infants in neonatology, where the implicated amino acid solution is commonly used, typically receive between 120 and $160 \mathrm{~mL} / \mathrm{kg}$ of fluids daily. ${ }^{11}$

In the study by Allwood and others," precipitate was not observed in a parenteral nutrition solution prepared with cysteine-containing amino acids and a product containing less copper (Peditrace, Pharmacia and Upjohn Ltd; $54 \mu \mathrm{g} / \mathrm{mL}$ copper chloride or $20 \mu \mathrm{g} / \mathrm{mL}$ elemental copper). The copper concentration in this solution, calculated in terms of elemental copper, amounted to about $157 \mu \mathrm{g} / \mathrm{L}$. The diluted parenteral nutrition solution that was tested in the current study would have provided $117 \mathrm{~mL} / \mathrm{kg}$ of fluids per day and $20 \mu \mathrm{g} / \mathrm{kg}$ of copper per day, which corresponds to a copper concentration of about $170 \mu \mathrm{g} / \mathrm{L}$. However, lack of visual observation of a precipitate does not rule out precipitation, because some precipitates cannot be detected visually. ${ }^{12}$ Allwood and others ${ }^{9}$ excluded precipitates from their test solution using a complex method that involved filtering the entire solution with a $0.45-\mu \mathrm{m}$ filter and examining the filter for precipitates with X-ray energy dispersive spectroscopy coupled to scanning electron microscopy. Following application of this methodology, no precipitate was found in their test solution.

For certain incompatibilities, temperature may affect the likelihood of precipitation. Generally, an increase in temperature increases solubility. However, for calcium phosphate, an increase in temperature favours precipitation. This phenomenon was highlighted in a previous report, which described body heat causing precipitation of calcium phosphate after the solution had passed through an in-line $0.22-\mu \mathrm{m}$ filter, ultimately resulting in occlusion of the catheter. ${ }^{13}$ However, subsequent analysis indicated that the compounded solution exceeded calcium phosphate solubility curves, which may have contributed to the precipitation. ${ }^{2}$ The effect of temperature was not explored in the 3 cases described here. It is possible that body heat affects the likelihood of precipitation, in which case the use of filters would not prevent adverse events.

\section{CONCLUSION}

This report has described a possible incompatibility between a cysteine-containing pediatric amino acid solution commonly used in neonatology and cupric sulphate in parenteral nutrition solutions. This incompatibility could potentially be avoided by limiting the copper concentration. Further investigations should aim to determine the exact mechanism by which the precipitate is formed and to provide more specific recommendations to avoid precipitation. Until better recommendations are available, it is considered prudent to limit the concentration of elemental copper to a maximum of $157 \mu \mathrm{g} / \mathrm{L}$ when using low-pH, cysteine-containing amino acid solutions. A $0.22-\mu \mathrm{m}$ filter should always be used when infusing 2 -in- 1 solutions, and a $1.2-\mu \mathrm{m}$ filter should always be used for 3-in-1 solutions. 


\section{References}

1. Mirtallo J, Canada T, Johnson D, Kumpf V, Petersen C, Sacks G, et al.; Task Force for the Revision of Safe Practices for Parenteral Nutrition. Safe practices for parenteral nutrition. JPEN J Parenter Enteral Nutr. 2004; 28(6):S39-70.

2. Newton DW, Driscoll DF. Calcium and phosphate compatibility: revisited again. Am J Health Syst Pharm. 2008;65(1):73-80.

3. ASHP guidelines on the safe use of automated compounding devices for the preparation of parenteral nutrition admixtures. Am J Health Syst Pharm. 2000;57(14):1343-8.

4. Curtis C, Sacks GS. Compounding parenteral nutrition: reducing the risks. Nutr Clin Pract. 2009;24(4):441-6.

5. Lavoie PM, Lavoie JC, Watson C, Rouleau T, Chang BA, Chessex P. Inflammatory response in preterm infants is induced early in life by oxygen and modulated by total parenteral nutrition. Pediatr Res. 2010;68(3):248-51.

6. Soghier LM, Brion LP. Cysteine, cystine or $N$-acetylcysteine supplementation in parenterally fed neonates. Cochrane Database Syst Rev. 2006;(4): CD004869.

7. Blackmer AB, Bailey E. Management of copper deficiency in cholestatic infants: review of the literature and a case series. Nutr Clin Pract. 2012;28(1):75-86.

8. Shike M. Copper in parenteral nutrition. Gastroenterology. 2009;137(5 Suppl):S13-7.

9. Allwood MC, Martin H, Greenwood M, Maunder M. Precipitation of trace elements in parenteral nutrition mixtures. Clin Nutr. 1998;17(5): 223-6.
10. Boddapati S, Yang K, Murty R. Intravenous solution compatibility and filter-retention characteristics of trace-element preparations. Am J Hosp Pharm. 1981;38(11):1731-6.

11. Corkins MR, Balint J; Pediatric nutrition support handbook. Silver Spring (MD): American Society for Parenteral and Enteral Nutrition; 2011.

12. Melchore JA. Sound practices for consistent human visual inspection. AAPS PharmSciTech. 2011;12(1):215-21.

13. Robinson LA, Wright BT. Central venous catheter occlusion caused by body-heat-mediated calcium phosphate precipitation. Am J Hosp Pharm. 1982;39(1):120-1.

Maxime Thibault, BPharm, MSC, CNSC, is a Pharmacist with the Centre hospitalier universitaire Sainte-Justine, Montréal, Quebec.

Competing interests: None declared.

Address correspondence to:

Maxime Thibault

CHU Sainte-Justine

3175, chemin Côte-Sainte-Catherine

Montréal QC H3T 1C5

e-mail: maxime.thibault.hsj@ssss.gouv.qc.ca

\begin{tabular}{|c|c|c|}
\hline & Ad Page & Prescribing Information \\
\hline Alveda Pharma / Corporate & IFC & - \\
\hline Baxter / Corporate & 99 & - \\
\hline Pfizer / Injectables & 94 & - \\
\hline Pfizer / Injectables & 96 & - \\
\hline Pharmaceutical Partners of Canada / Corporate & $\mathrm{OBC}$ & - \\
\hline
\end{tabular}

